D. BOCHENEK*\# ${ }^{*}$ P. NIEMIEC* ${ }^{*}$ M. ADAMCZYK*, R. SKULSKI*, R. ZACHARIASZ*,

B. WODECKA-DUŚ*, Z. MACHNIK*

\title{
THE MULTICOMPONENT PZT-TYPE CERAMICS FOR MICROMECHATRONIC APPLICATIONS
}

\begin{abstract}
In the paper two compositions of the multi-component PZT-type ceramics admixtures by $\mathrm{Mn}^{4+}, \mathrm{Sb}^{3+}, \mathrm{W}^{6+}, \mathrm{Ni}^{2+}$ were presented. The ceramic powders were synthesized by the calcination of powders while their densification was carried out by free sintering method. The dielectric, ferroelectric, piezoelectric studies and DC electrical conductivity of the multicomponent PZT-type samples were presented. The results of the multi-component ceramics predispose these type materials in micromechatronic and microelectronic applications for example as element of the actuators.

Keywords: multicomponent PZT-type ceramics, piezoelectrics, micromechatronics, actuators
\end{abstract}

\section{Introduction}

In modern microelectronics and micromechatronics piezoelectric ceramic elements as well as multiferroic ceramic materials are more common and universally used [1-4]. The possibility of their functional use depends on the stability of the piezoelectric parameters in both time, temperature and under the influence of various external factors. One group of materials that meet the newer and more functional requirements for applications are multicomponent solid solutions obtained on the basis $(1-x) \mathrm{PbZrO}_{3}-(x) \mathrm{PbTiO}_{3}$ [5]. Multicomponent ceramic materials based on PZT-type can be designed with the entire area of the phase diagram for specific applications, e.g.: for the construction of high-frequency and low-frequency transducers, high-temperature and high stability of the piezoelectric parameters transducers, transducers with high sensitivity to mechanical stress as well as electroacoustic transducers, optoelectronic piezotransformers, actuators, accelerometers, piezoelectric motors and sensors, etc. [6-8]. Particularly interesting, due the optimal and high piezoelectric properties, are ceramic materials close to the morphotropic boundary [9]. For decades, as the electronic components PZT-type materials have been produced in the form of solid ceramics, powders, thin films, ceramic composites, etc. $[10,11]$. Presented work aimed to obtain and examine the basic properties of the multicomponent solid solutions of the PZT-type materials for applications in micromechatronics and microelectronics.

\section{Experiment}

In the research the multicomponent PZT-type solid solutions doped by $\mathrm{Mn}^{4+}, \mathrm{Sb}^{3+}, \mathrm{W}^{6+}, \mathrm{Ni}^{2+}$ were obtained and investigated. The following chemical compositions were designed:

(i) $\mathrm{Pb}\left[\left(\mathrm{Zr}_{0.49} \mathrm{Ti}_{0.51}\right)_{0.94} \mathrm{Mn}_{0.015} \mathrm{Sb}_{0.013} \mathrm{~W}_{0.012} \mathrm{Ni}_{0.02}\right] \mathrm{O}_{3}(\mathrm{C}-1)$;

(ii) $\mathrm{Pb}\left[\left(\mathrm{Zr}_{0.49} \mathrm{Ti}_{0.51}\right)_{0.94} \mathrm{Mn}_{0.02} \mathrm{Sb}_{0.016} \mathrm{~W}_{0.014} \mathrm{Ni}_{0.01}\right] \mathrm{O}_{3}(\mathrm{C}-2)$.

The ceramic multicomponent compounds were obtained using a conventional ceramic technology for the PZT-like materials using simple oxides: $\mathrm{PbO}$ (99.99\% purity), $\mathrm{ZrO}_{2}$ (99.00\% purity), $\mathrm{TiO}_{2}$ (99.99\% purity), $\mathrm{WO}_{3}$ (99.90\% purity), $\mathrm{Sb}_{2} \mathrm{O}_{3}(99.90 \%$ purity), $\mathrm{MnO}_{2}$ (99.00\% purity) and $\mathrm{NiO}(99.80 \%$ purity). The starting powders were mixed for $24 \mathrm{~h}$ in ethyl alcohol using a planetary ball mill (FRITSCH Pulwerisette 6). After drying the mixtures of powders were synthesized by calcination method at following conduction $T_{\text {calc }}=850^{\circ} \mathrm{C}, t_{\text {calc }}=4 \mathrm{~h}$. Compaction (densification) was carried out by the free sintering method $\left(T_{s}=1150^{\circ} \mathrm{C}, t_{s}=2 \mathrm{~h}\right.$, at a heating rate of $\left.150^{\circ} \mathrm{C} / \mathrm{h}\right)$. The final steps of technology PZT type solid solutions were grinding, polishing, removing mechanical stresses (annealing at temperature $700^{\circ} \mathrm{C}$ ) and for electrical testing putting silver paste electrodes onto both surfaces of the samples.

In order to determine the optimal conditions of synthesis starting powder of the PZT-type material were used thermal analysis DTA, as well as DTG and TG, using a Q-1500D derivatograph (in the temperature range from 20 to $1030^{\circ} \mathrm{C}$ ). EDS analysis and SEM microstructure of the ceramic samples were carried out using JEOL JSM-7100 TTL LV Field Emission Scanning Electron Microscope. Temperature dielectric parameters were measured using a capacity bridge LCR Meter (QuadTech

\footnotetext{
UNIVERSITY OF SILESIA, INSTITUTE OF TECHNOLOGY AND MECHATRONICS, 12 ŻYTNIA STR., 41-200 SOSNOWIEC, POLAND

Corresponding author: dariusz.bochenek@us.edu.pl
} 
1920 Precision), by means of heating cycle at frequencies of the measurement field from $v=1 \mathrm{kHz}$ to $1 \mathrm{MHz}$. Ferroelectric researches (hysteresis $P-E$ loops) were carried out by a SawyerTower circuit and using high voltage amplifier (Matsusada Inc. HEOPS-5B6 precision). Data in digital form were written using an $\mathrm{A} / \mathrm{D}, \mathrm{D} / \mathrm{A}$ transducer card. Electromechanical studies have been conducted using an optical displacement meter (Philtec Inc., D63) and a HEOPS-5B6 high voltage amplifier. The data were stored on a computer disc using an $\mathrm{A} / \mathrm{D}, \mathrm{D} / \mathrm{A}$ transducer card and the LabView computer program. DC electric conductivity study was carried out by a $6517 \mathrm{~B}$ Keithley electrometer (in temperatures range from $20^{\circ} \mathrm{C}$ to $450^{\circ} \mathrm{C}$ ).

\section{Results and discussion}

The temperature of synthesis was determined with DTA/ TG analysis (Fig. 1). The DTA results show that the synthesis of the components of the analyzed material powders occurs to a temperature of $774^{\circ} \mathrm{C}(\mathrm{C}-1)$ and $765^{\circ} \mathrm{C}(\mathrm{C}-2)$. Based on the studies, the optimal conditions for the synthesis powders were determined: $T_{\text {synth }}=850^{\circ} \mathrm{C}$ and $t_{\text {synt }}=4 \mathrm{~h}$. On the TG curve can be observed characteristic changes associated with the weight loss of the sample during the heating. For two multicomponent samples the extreme weight loss falls on the temperature about $400^{\circ} \mathrm{C}$ and loss of mass is $0.3 \%$ and $1.3 \%$ for $\mathrm{C}-1$ and $\mathrm{C}-2$ samples respectively. DTG curve shows the change in the rate of decomposition of the substances with increasing temperature. The accompanying local minima on the DTG curve indicate the areas the temperatures at which the weight loss is the fastest. The first minimums (below $100^{\circ} \mathrm{C}$ ) seen on the DTG curves are associated with loss of moisture samples, confirming occurring changes in the DTA curves. Further minimums are associated with the formation of the perovskite PZT-like structure as well as several intermediate phases. The strong peak visible in the temperature $621^{\circ} \mathrm{C}(\mathrm{C}-1)$ and $623^{\circ} \mathrm{C}(\mathrm{C}-2)$ is associated with formation the pyrochlore phase in the PZT-type material. High-temperature heating during synthesis prevents the formation the foreign (pyrochlore) phase.
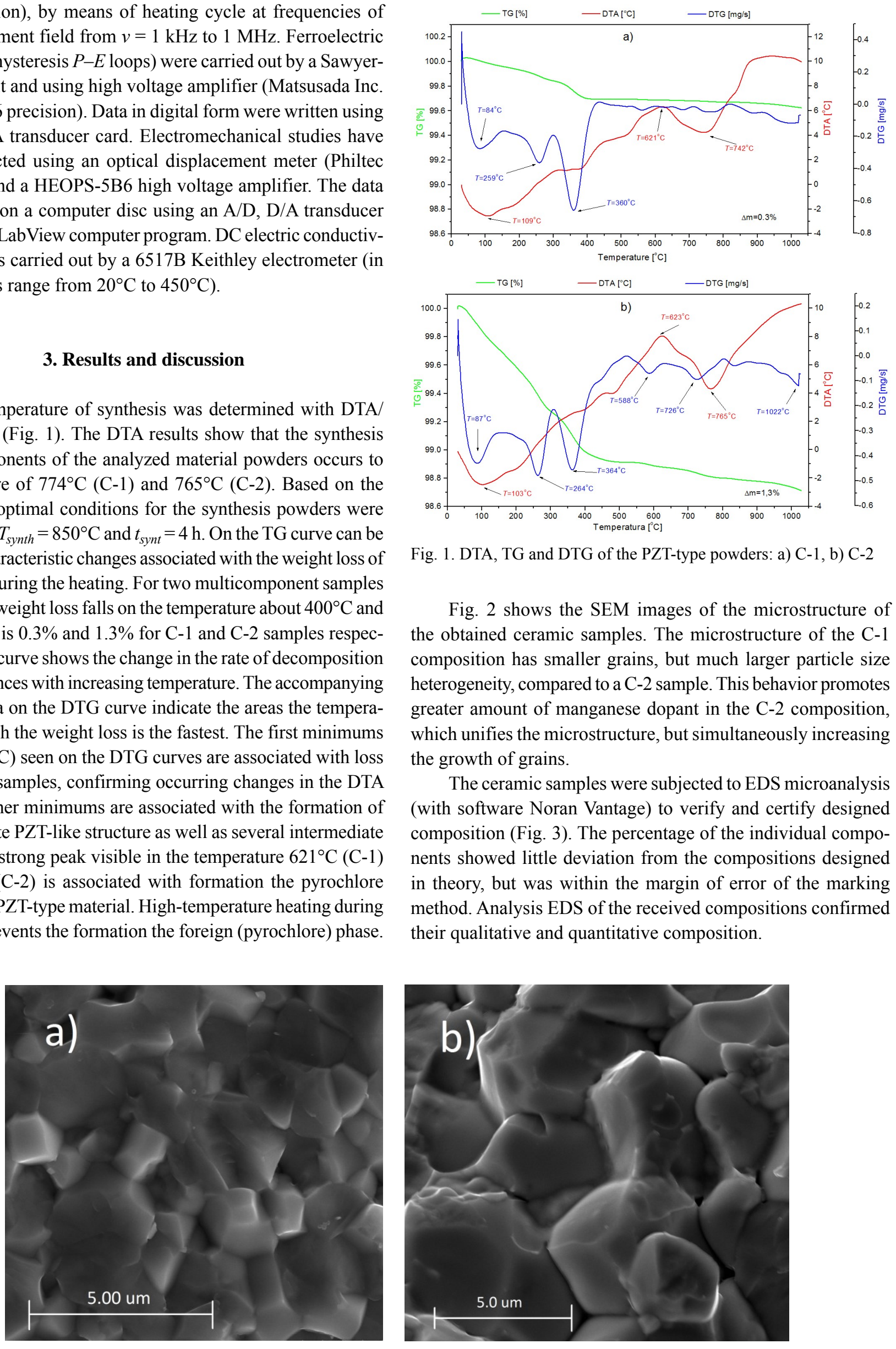

Fig. 1. DTA, TG and DTG of the PZT-type powders: a) C-1, b) C-2 the obtained ceramic samples. The microstructure of the C-1 composition has smaller grains, but much larger particle size heterogeneity, compared to a $\mathrm{C}-2$ sample. This behavior promotes greater amount of manganese dopant in the C-2 composition, which unifies the microstructure, but simultaneously increasing the growth of grains. (with software Noran Vantage) to verify and certify designed composition (Fig. 3). The percentage of the individual components showed little deviation from the compositions designed in theory, but was within the margin of error of the marking method. Analysis EDS of the received compositions confirmed their qualitative and quantitative composition.

Fig. 2. SEM microstructure of the ceramic samples: a) C-1, b) C-2

Fig. 2 shows the SEM images of the microstructure of

The ceramic samples were subjected to EDS microanalysis 



Fig. 3. EDS spectrum of ceramic samples: a) C-1, b) C-2

Temperatures testing of the DC electrical conductivity of the $\mathrm{C}-1$ and $\mathrm{C}-2$ ceramics were conducted in the temperature range from room temperature to $450^{\circ} \mathrm{C}$ (Fig. 4). The $\ln \sigma_{D C}(1 / T)$ graph shows that at about a temperatures of the phase transition for the obtained materials there are characteristic inflection curves, which divides the graph into two parts with different values of the activation energy: the area I of a lower temperature and area II of a higher temperature. In these areas $E_{A c t}$ values of activation energy were calculated according to the Arrhenius law:

$$
\sigma_{D C}=\sigma_{0} e^{-\frac{E_{A c t}}{k_{B} T}}
$$

where: $k_{B}$-Boltzmann constant, $E_{A c t}-$ activation energy, $T-$ absolute temperature. The values of activation energy calculated from the slope of the $\ln \sigma_{D C}(1000 / T)$ are summarized in Fig. 4 and in Table 1. Above $T_{C}$ temperature there are higher values of $E_{A c t}$, which is characteristic for the materials with perovskitetype structure. Higher values of the $E_{A c t}$ have the samples of the composition C-1, compared with the sample of C-2 composition.

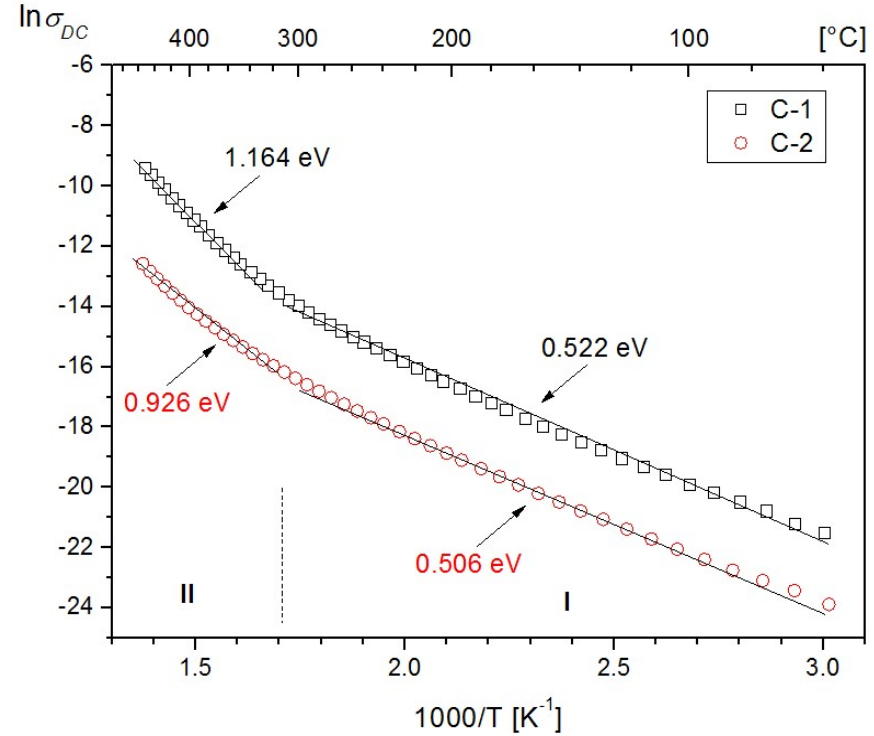

Fig. 4. The $\ln \sigma_{D C}(1000 / T)$ relationship for the PZT-type solid solutions: $\mathrm{C}-1$ and $\mathrm{C}-2$
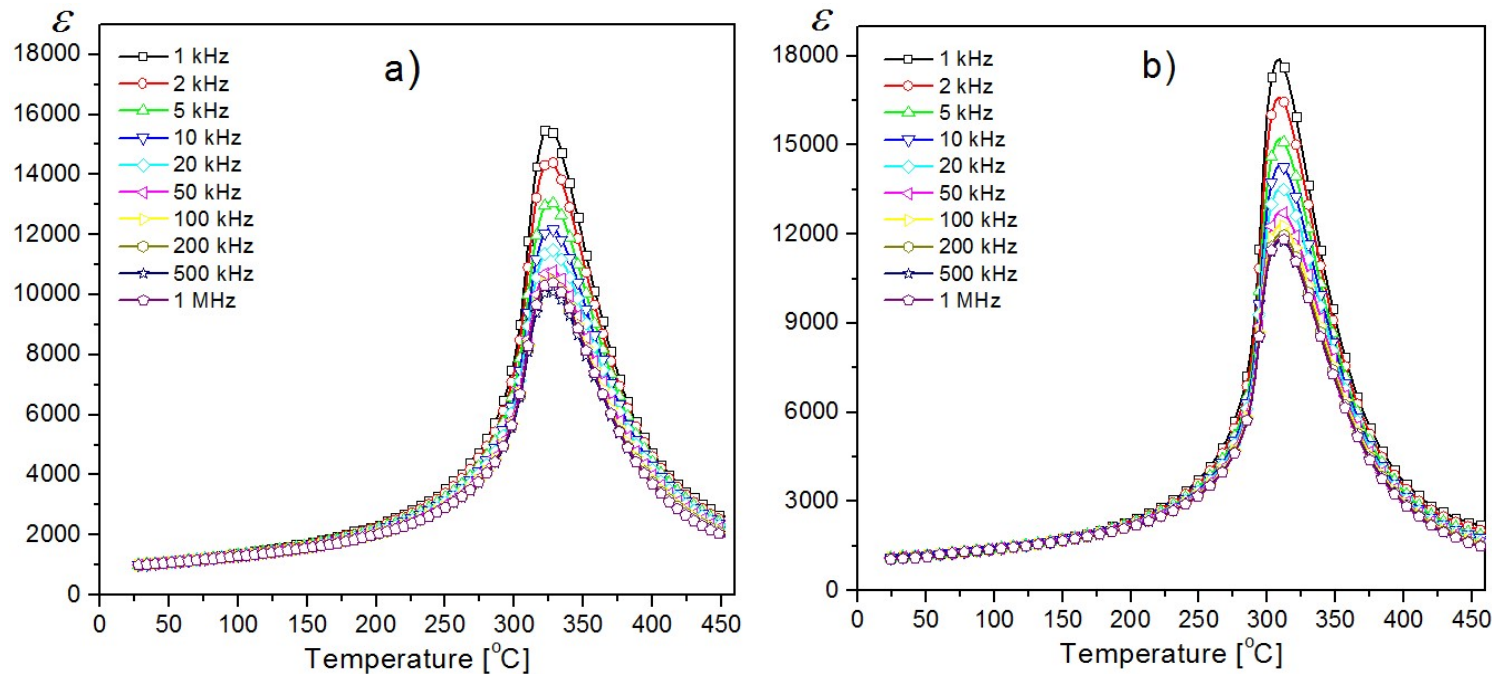

Fig. 5. Temperature dependencies of the dielectric permittivity for PZT-type solid solutions: a) C-1, b) C-2 
The temperature dependences of dielectric permittivity $(\varepsilon)$ for the obtained solid solutions are presented in Fig. 5. High values of the maximum dielectric permittivity $\left(\varepsilon_{\max }\right)$ can be observed. The investigation results show that with reference to the base chemical composition, larger amounts of $\mathrm{MnO}_{2}, \mathrm{Sb}_{2} \mathrm{O}_{3}$ and $\mathrm{WO}_{3}$ increases the value of $\varepsilon_{\max }$ as well as shifts temperature of the transition towards a lower temperature. Presented frequency measurements did not show temperature shift of the phase transition for the obtained samples. The temperatures of the phase transition and characteristic dielectric parameters are presented in Table 1.

TABLE 1

Values of the parameters of the multicomponent PZT-type samples (dielectric studies were carried out for $v=1 \mathrm{kHz}$ )

\begin{tabular}{|c|c|c|}
\hline \hline & C-1 & C-2 \\
\hline$\rho\left[\mathrm{g} / \mathrm{cm}^{3}\right]$ & 6.55 & 7.22 \\
\hline$T_{C}\left[{ }^{\circ} \mathrm{C}\right]$ & 325 & 309 \\
\hline$\varepsilon_{r}$ at $T_{r}$ & 1027 & 1125 \\
\hline$\varepsilon_{\max }$ at $T_{C}$ & 15500 & 17870 \\
\hline $\tan \delta$ at $T_{r}$ & 0.014 & 0.006 \\
\hline $\tan \delta$ at $T_{C}$ & 0.177 & 0.175 \\
\hline$\rho_{D C}$ at $T_{r}[\mathrm{Wm}]$ & $2.6 \times 10^{8}$ & $1.2 \times 10^{9}$ \\
\hline$E_{A c t}$ in I $[\mathrm{eV}]$ & 0.522 & 0.506 \\
\hline$E_{A c t}$ in $\mathrm{II}[\mathrm{eV}]$ & 1.164 & 0.926 \\
\hline$H_{S}[\%]$ & 68.01 & 54.23 \\
\hline$S_{\text {rest }}[\%]$ & 0.031 & 0.044 \\
\hline$d_{33}[\mathrm{pC} / \mathrm{N}]$ & 217 & 377 \\
\hline$g_{33} \times 10^{-3}[\mathrm{Vm} / \mathrm{N}]$ & 9.05 & 15.23 \\
\hline
\end{tabular}

The values of the dielectric loss $(\tan \delta)$ for the obtained multicomponent solid solusions are relatively low (Fig. 6). The temperature dependences of the dielectric loss are characteristic for perovsite-type materials on the base PZT. On the curves just before the phase transition is observed an increase and then decrease in values of dielectric loss. Above the temerature $370^{\circ} \mathrm{C}$ dielectric loss increases rapidly, what is connected with an increase in electric conductivity in higer temperatures. This type measurements were carried out in [12], however, the values of dielectric loss of the obtained materials were higher.

Plot of sum hysteresis loops $P-E$ of the multicomponent PZT-type ceramics (for frequency $v=1 \mathrm{~Hz}$ ) at room temperature are presented in Fig. 7. The ceramic samples have wide hysteresis loops, with coercive field $E_{C}$ equal to $1.44 \mathrm{kV} / \mathrm{mm}$ for the $\mathrm{C}-1$ and 1.23 for the $\mathrm{C}-2$ material. The $\mathrm{C}-1$ sample exhibits higher values of spontaneous polarization $P_{s}\left(16.07 \mu \mathrm{C} / \mathrm{cm}^{2}\right)$ and remnant polarization $\left(11.90 \mu \mathrm{C} / \mathrm{cm}^{2}\right)$, compared with the second samples $\mathrm{C}-2$, where the values are $17.20 \mu \mathrm{C} / \mathrm{cm}^{2}$ and $13.90 \mu \mathrm{C} / \mathrm{cm}^{2}$ respectively.

Fig. 8 shows the bipolar electric field-induced strain loops unpolarized in the room temperature for the C-1 and C-2 samples. The $S$ - $E$ electromechanic loops for the obtained materials take on the "butterfly wings" characteristic shape, and show practically linear relation $S(E)$, which indicates the piezoelectric nature of the strain. In case of the C-1 sample, in a maximum field of $3.5 \mathrm{kV} / \mathrm{mm}$, is observed small asymmetry of deformation. The $S-E$ loops for obtained materials demonstrate mean values of $S_{\text {rest }}$ residual strain and $H_{S}$ hysteresis (Table 1 ). The C-2 ceramics shows higher values of the $S_{\text {rest }}$ residual strain in comparison with the C-1 ceramics. The strain hysteresis coefficient according [13] was calculated using the formula:

$$
H_{S}=\frac{\Delta S_{\text {half }} * 100 \%}{S_{\max }}
$$

where: $\Delta S_{\text {half }}$ is the hysteresis of strains (the difference between maximum and minimum strain value for the half of the maximum electric field), $S_{\max }$ is strain for the maximum of the applied electric field.

The $d_{33}$ piezoelectric coefficient of the PZT-type solid solutions was calculated as a maximal value of derivative $\frac{\partial S}{\partial E}$ obtained from $S-E$ electromechanic loops. The piezoelectric coefficient was measured under $2 \mathrm{kV} / \mathrm{mm}$ electric field and frequency $0.1 \mathrm{~Hz}$ is $217 \mathrm{pC} / \mathrm{N}$ and $377 \mathrm{pC} / \mathrm{N}$ for $\mathrm{C}-1$ and $\mathrm{C}-2$
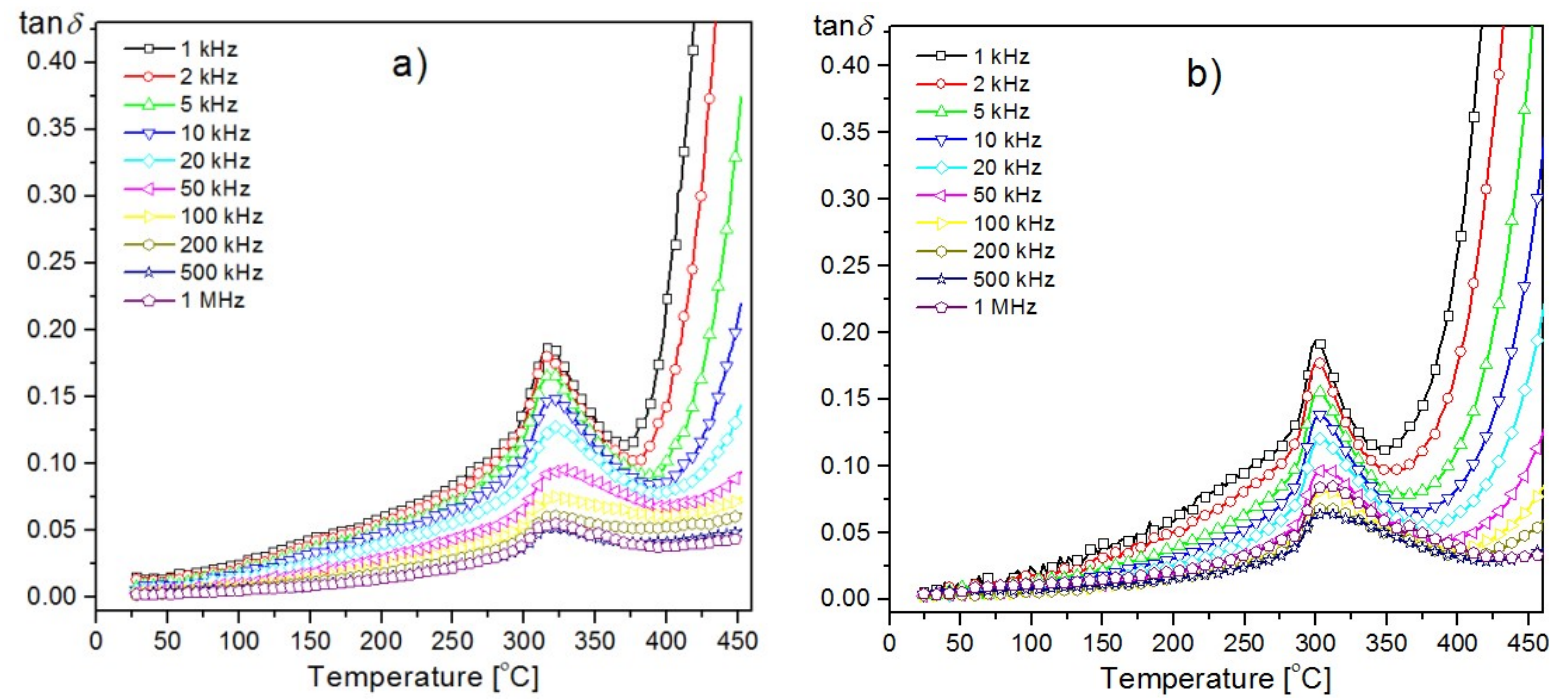

Fig. 6. Temperature dependencies of the dielectric loss of the PZT-type solid solutions: a) C-1, b) C-2 


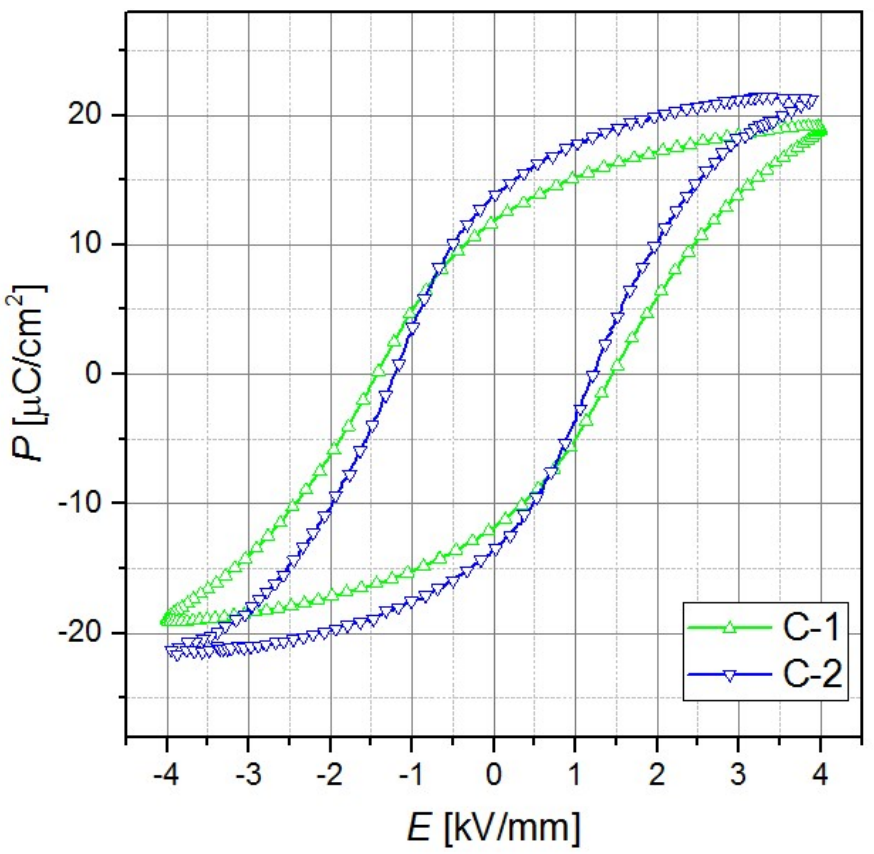

Fig. 7. Plot of hysteresis loops $P-E$ of the $\mathrm{C}-1$ and $\mathrm{C}-2$ samples (at room temperature and frequency of $1 \mathrm{~Hz}$ )
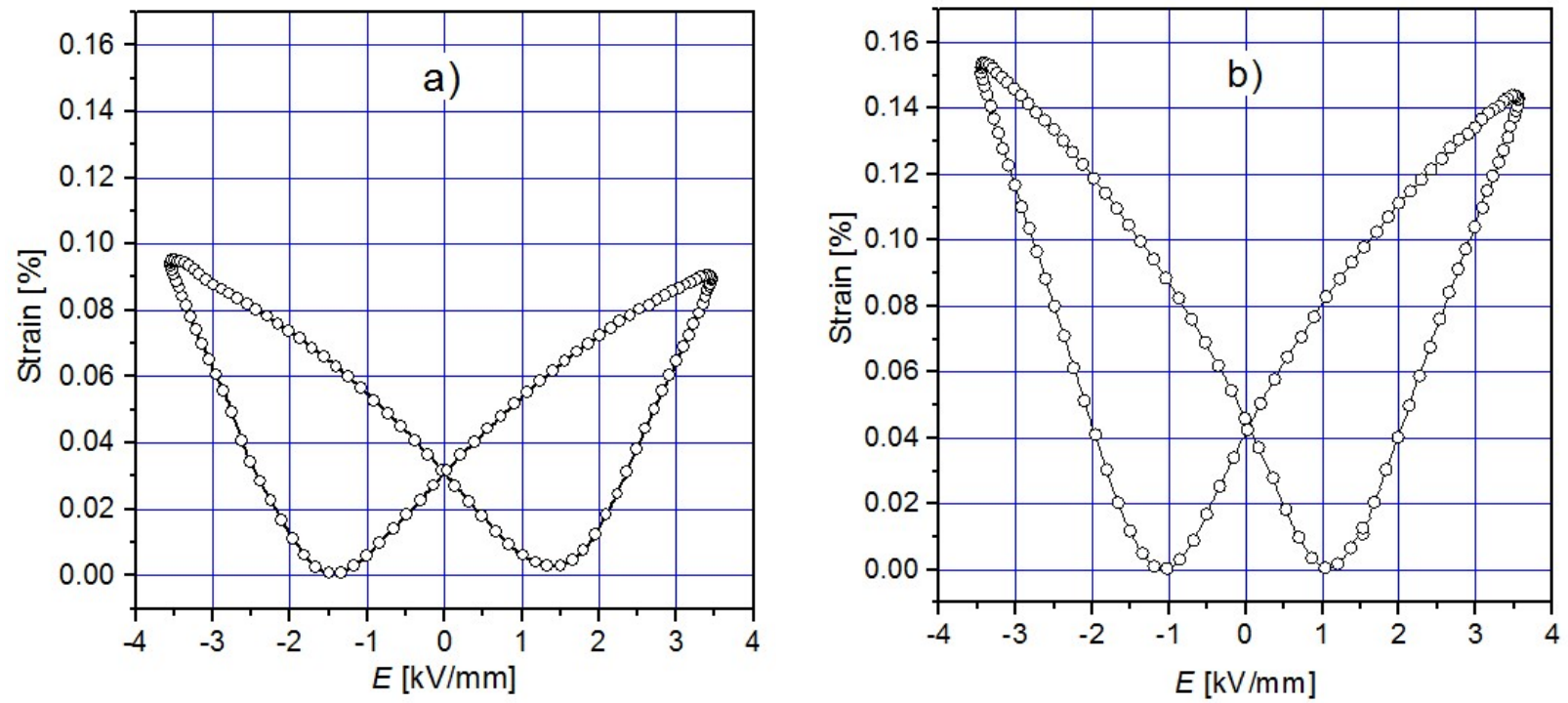

Fig. 8. Bipolar strain-electric field loops $(S-E)$ for C-1 and C-2 samples measured at room temperature, under electric field $3.5 \mathrm{kV} / \mathrm{mm}$ (frequency of $0.1 \mathrm{~Hz}$ )

sample, respectively. Larger quantities of admixtures such as manganese, antimony and tungsten in the composition of PZT material have a positive impact on the piezoelectric parameters of the ceramic samples.

\section{Conclusions}

In the present work were obtained successfully the multicomponent PZT-type solid solutions doped by $\mathrm{Mn}^{4+}, \mathrm{Sb}^{3+}, \mathrm{W}^{6+}$, $\mathrm{Ni}^{2+}$. Two chemical compositions were designed: $\mathrm{Pb}\left[\left(\mathrm{Zr}_{0.49}\right.\right.$ $\left.\left.\mathrm{Ti}_{0.51}\right)_{0.94} \mathrm{Mn}_{0.015} \mathrm{Sb}_{0.013} \mathrm{~W}_{0.012} \mathrm{Ni}_{0.02}\right] \mathrm{O}_{3}(\mathrm{C}-1), \mathrm{Pb}\left[\left(\mathrm{Zr}_{0.49} \mathrm{Ti}_{0.51}\right)_{0.94}\right.$ $\left.\mathrm{Mn}_{0.02} \mathrm{Sb}_{0.016} \mathrm{~W}_{0.014} \mathrm{Ni}_{0.01}\right] \mathrm{O}_{3}(\mathrm{C}-2)$. The microstructure of the
C-1 sample has smaller grains, but much larger heterogeneity of the particle size compared to the C-2 sample. The greater amount of manganese dopant at the same time causes the growth of grains.

The ceramic samples exhibit high values of dielectric permittivity both at room temperature as well as high as the phase transition temperature. In addition, the temperature dependences of the dielectric properties showed that obtained materials have low dielectric loss. Increasing the amount of dopant tungsten $\mathrm{W}$ and antimony $\mathrm{Sb}$ in multicomponent solid solutions of PZT-type reduces the coercivity field. Bipolar strain-electric field loops for the obtained compositions show practically linear relation $S(E)$ and are typical for piezoelectric materials on the PZT 
based. Comprehensive studies have shown that higher amounts of additives Mn manganese, Sb antimony and W tungsten, also affect favorably on piezoelectric parameters in multicomponent PZT-type materials.

Performed tests of the multi-component PZT-type material showed that the parameters of all the ceramic samples predispose them to modern applications. High value of the dielectric and piezoelectric parameters are necessary for applications in the area of micromechatronics and microelectronics e.g. as an element to build actuators and piezoelectric transducers.

\section{REFERENCES}

[1] K. Uchino, J.R. Giniewicz, Micromechatronics, New York, Marcel Dekker, 2003.

[2] A.J. Moulson, J.M. Herbert, Electroceramics, Materials, Properties, Applications, second ed., Wiley, Chichester, West Sussex, 2003.

[3] D. Bochenek, Z. Surowiak, Applications of iron (III) nitrate to obtain the multiferroic $\mathrm{Pb}\left(\mathrm{Fe}_{1 / 2} \mathrm{Nb}_{1 / 2}\right) \mathrm{O}_{3}$ ceramics by the sol-gel method; Journal of Alloys and Compounds 480, 732-736 (2009).

[4] H.S. Tzou, H.J. Lee, S.M. Arnold, Smart materials, precision sensors/Actuators, Smart Structures, and Structronic Systems, Mechanics of Advanced Materials and Structures 11, 367-393 (2014).

[5] M.R. Soares, A.M.R. Senos, P.Q. Mantas, Phase coexistence region and dielectric properties of PZT ceramics, Journal of the European Ceramic Society 20, 321-334 (2000).
[6] Y. Xu, Ferroelectric Materials and Their Applications, North-Holland, Amsterdam, 1991.

[7] P.K. Panda, B. Sahoo, S. Raja, M.P. Vijaya Kumar, V. Shankar, Electromechanical and dynamic characterization of in-house-fabricated amplified piezo actuator, Smart Materials Research 2012, 203625 (2012)

[8] W. Hong-Wei, Performance Simulation and Fabrication of PZT Piezoelectric Composite Ring, International Journal of Materials Science and Applications 5, 2, 89-94 (2016).

[9] P.K. Panda, B. Sahoo, PZT to Lead Free Piezo Ceramics: A Review, Ferroelectrics 474, 128-143 (2015).

[10] D. Bochenek, R. Zachariasz, P. Niemiec, J. Ilczuk, J. Bartkowska, D. Brzezińska, Ferroelectromagnetic solid solutions on the base piezoelectric ceramic materials for components of micromechatronics, Mechanical Systems and Signal Processing 78, 1 84-90 (2016).

[11] X. Li, J.S. Vartuli, D.L. Milius, I. A. Aksay, W.Y. Shih, W.H. Shih, Electromechanical Properties of a Ceramic $\mathrm{d}_{31}$-Gradient Flextensional Actuator, J. Am. Ceram. Soc. 84, 5, 996-1003 (2001).

[12] N. Texier, C. Courtois, M. Traianidis, A. Leriche, Power process influence on the characteristics of $\mathrm{Mn}, \mathrm{W}, \mathrm{Sb}, \mathrm{Ni}$-doped PZT, Journal of The European Ceramic Society 21, 1499-1502 (2001).

[13] D. Bochenek, P. Kruk, R. Skulski, P. Wawrzała, Multiferroic ceramics $\mathrm{Pb}\left(\mathrm{Fe}_{1 / 2} \mathrm{Nb}_{1 / 2}\right) \mathrm{O}_{3}$ doped by $\mathrm{Li}$, Journal of Electroceramics 26, 8-13,(2011). 